\title{
Allopolyploid vs. autopolyploid origins in the genus Lathyrus (Leguminosae) $\dagger$
}

\author{
J. F. GUTIÉRREZ*, F. VAQUERO \& F. J. VENCES \\ Departamento de Genética, Facultad de Biologia, Universidad de León, E-24071 León, Spain
}

\begin{abstract}
Allopolyploid vs. autopolyploid origins of polyploid species of the genus Lathyrus have been tested by the C-banding technique and electrophoretical procedures for 11 genetic loci belonging to six isozyme systems. Results of both experiments suggest for the polyploid populations of $L$. palustris and $L$. pratensis an autopolyploid origin from their respective diploid counterparts. Nevertheless, $L$. venosus seems to have originated through allopolyploidy involving two sympatric diploid species, L. ochroleucus and L. palustris.
\end{abstract}

Keywords: C-banding karyotype, genetic distance, isozyme, Lathyrus, origin, polyploidy.

\section{Introduction}

The genus Lathyrus contains about 150 species principally distributed in the temperate and tropical regions of both hemispheres (Alkin et al., 1985; Narayan, 1991).

Two peculiar chromosomal characteristics have been observed in species included in this genus. Firstly, in spite of the large number of species indicated above, only one, $L$. venosus Müh., has been considered as polyploid $(2 n=4 x=28)$. Secondly, a limited number of them, like L. pratensis L. and L. palustris L., show an interpopulational polymorphism for ploidy level. Thus, diploid and tetraploid populations $(2 n=2 x=14$ and $2 n=4 \mathrm{x}=28$ ) have been described in L. pratensis and diploid and hexaploid $(2 n=2 x=14$ and $2 n=6 x=42)$ in L. palustris.

Lathyrus pratensis is a wild perennial species that is native in Europe, Asia and North Africa and has been introduced into America. Tetraploid populations grow in the west of the British Isles. Tetraploid and diploid populations are sympatric in some regions of the Netherlands, Belgium and France.

Lathyrus palustris is a perennial species that occurs naturally in Asia and northern Europe and has also been introduced into North America (Kupicha, 1983). Hexaploid populations are widely distributed; the

*Correspondence.

† To Barbara Stebbins, in memoriam. diploid ones, however, are limited to the north-west of the Iberian peninsula and south Alaska.

Lathyrus venosus is a perennial species that grows in Canada and in the north of the U.S.A.

While all polyploid species of Lathyrus are perennial and geographically distributed in cold and humid regions of the northern hemisphere, diploid species are generally annuals distributed in xeric regions. This climatic pattern of distribution agrees with the hypothesis that polyploid species are more adaptable to a wider range of environmental conditions (Stebbins, 1989), a fact which could be attributed to their genetic plasticity and hardiness compared with their progenitors.

According to some authors all the polyploid species and populations have an autopolyploid origin (Narayan, 1991) but others (G. L. Stebbins, personal communication) propose an allopolyploid origin for $L$. venosus from the two sympatric and diploid species $L$. palustris and $L$. ochroleucus L. $(2 n=2 x=14)$. The latter is a perennial species, widely distributed along the east-west border between Canada and the U.S.A. (Kupicha, 1983).

Unfortunately there are few published data on the cytogenetics and molecular markers of these species of Lathyrus that could be useful to discriminate between an allopolyploid vs. autopolyploid origin of polyploid populations.

In this paper we present data on cytogenetic characters and isozyme markers of populations of these four species that support the allopolyploid origin for $L$. venosus and the autopolyploid origin of polyploid populations of L. pratensis and L. palustris. 


\section{Materials and methods}

\section{Materials}

The materials used in this work included several samples of $L$. pratensis, $L$. palustris, $L$. venosus and $L$. ochroleucus (Table 1). Some samples were collected in diverse regions of Spain and others were kindly provided by different Germplasm Banks, Botanical Gardens and research workers.

\section{Cytogenetic methods}

The chromosome number of each accession was estimated over a sample of ten individuals by conventional Feulgen-staining of root-tips.

Karyotypes of different species were constructed by taking into account 12 chromosomal characteristics observed on mitotic chromosomes of root-tips stained by a Giemsa C-banding procedure (Alvarez et al., 1991) (Figs 1 and 2): centromeric index, telomeric

Table 1 Material

\begin{tabular}{|c|c|c|c|}
\hline Species & $\begin{array}{c}\text { Chromosome } \\
\text { number }\end{array}$ & $\begin{array}{l}\text { Life } \\
\text { cycle }\end{array}$ & Origin* \\
\hline L. ochroleucus & $2 n=2 x=14$ & Perennial & $\begin{array}{l}\text { Alberta-3 (CAN) } \\
\text { N. Dakota (USA) } \\
\text { Alberta-1 (CAN) } \\
\text { Alberta-2 (CAN) }\end{array}$ \\
\hline L. palustris & $2 n=6 x=42$ & Perennial & $\begin{array}{l}\text { Cantabria-1 (SP) } \\
\text { Cantabria-3 (SP) } \\
\text { Cantabria-5 (SP) } \\
\text { Cantabria-M (SP) } \\
\text { Cantabria-6 (SP) } \\
\text { R.B.G. Kew (UK) }\end{array}$ \\
\hline L. pratensis & $2 n=4 x=28$ & Perennial & $\begin{array}{l}\text { Berlin (GER) } \\
\text { Bayreuth (GER) } \\
\text { R.B.G. Kew (UK) } \\
\text { Lorraine-6 (FR) } \\
\text { Lorraine (FR) } \\
\text { Lorraine-3 (FR) } \\
\text { Lorraine-7 (FR) } \\
\text { Lorraine-8 (FR) } \\
\text { Prague (CZH) } \\
\text { Osnabruck (GER) } \\
\text { Hamburg (GER) } \\
\text { León-A (SP) } \\
\text { Frankfurt (GER) } \\
\text { León-C (SP) } \\
\text { Castellmont (SP) } \\
\text { Geneva (SWI) } \\
\text { R. Marche (ITA) } \\
\text { Cantabria-1 (SP) } \\
\text { Cantabria-2 (SP) } \\
\text { Cantabria-3 (SP) } \\
\text { Cantabria-4 (SP) } \\
\text { Cantabria-5 (SP) } \\
\text { León-P (SP) }\end{array}$ \\
\hline L. venosus & $2 n=4 x=28$ & Perennial & $\begin{array}{l}\text { Alberta (CAN) } \\
\text { Minneapolis (USA) } \\
\text { West Virginia (USA) }\end{array}$ \\
\hline
\end{tabular}

*CAN: Canada; CZH: Czechoslovakia; FR: France; SP: Spain; SWI: Switzerland; UK: United Kingdom; USA: United States of America. 
L. palustris $2 n=6 x=42$

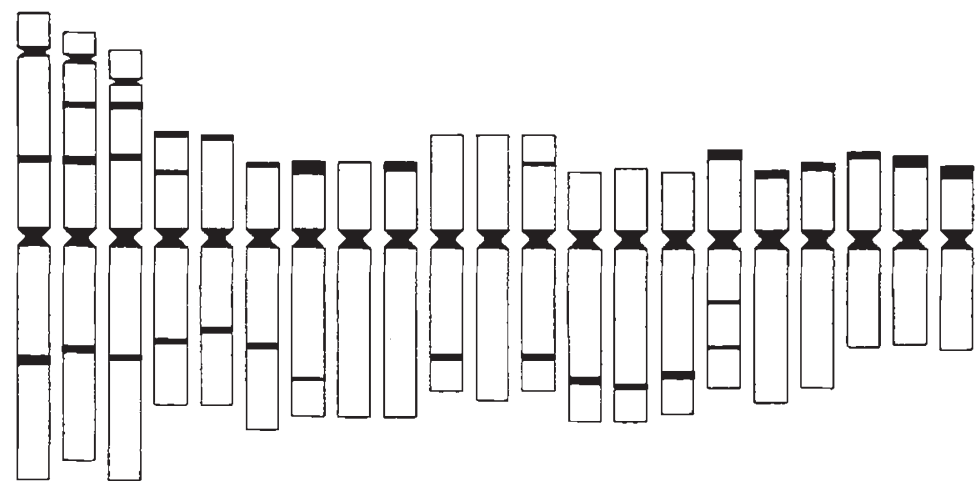

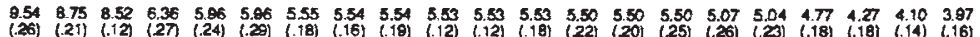
$\begin{array}{llllllllllllllllllllll}58.1 & 54.4 & 62.6 & 56.1 & 58.9 & 71.4 & 72.0 & 71.3 & 71.1 & 57.5 & 57.8 & 57.5 & 71.8 & 71.9 & 71.8 & 61.5 & 70.6 & 66.6 & 53.3 & 53.6 & 59.9 \\ (2.6) & (2.5) & (2.3) & (1.1) & (2.3) & (1.2) & (2.1) & (1.2) & (1.8) & (1.4) & (1.3) & (1.8) & (1.3) & (1.7) & (1.1) & (2.4) & (1.2) & (1.4) & (1.7) & (2.3) & (1.5)\end{array}$

1pa 2pa 3pa 4pa 5pa 6pa 7pa 8pa 9pa 10pa $11 p a$ 12pa 13pa 14pa 15pa 16pa17pa 18pa 19pa20pa21pa

L. pratensis $2 \mathrm{n}=4 \mathrm{x}=28$

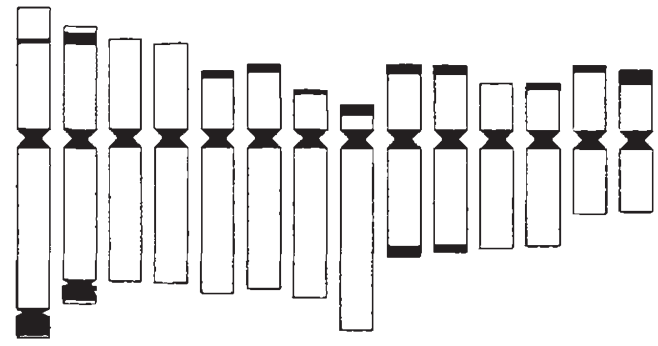

$\begin{array}{lllllllllllllll}6.85 & 5.64 & 5.48 & 5.33 & 5.03 & 5.01 & 4.72 & 4.70 & 4.57 & 4.42 & 3.81 & 3.80 & 3.35 & 3.24 \\ (.34) & (.22) & (.35) & (.44) & (.18) & (.25) & (.15) & (.31) & (.37) & (.14) & (.41) & (.27) & (.19) & (.21)\end{array}$ $\begin{array}{llllllllllllll}57.5 & 48.1 & 58.4 & 60.0 & 69.5 & 66.8 & 77.3 & 87.4 & 50.8 & 58.6 & 67.1 & 65.5 & 522 & 51.5 \\ \text { (1.3) } & (21) & (2.6) & (1.8) & (1.8) & (1.4) & (1.8) & (1.8) & (2.5) & (1.5) & (2.1) & (1.7) & (3.1) & (1.2)\end{array}$

$1 p r 2 p r 3 p r$ 4pr 5pr 6pr 7pr 8pr 9pr 10pr 11pr 12pr 13pr 14pr

L. venosus $2 \mathrm{n}=4 \mathrm{x}=28$

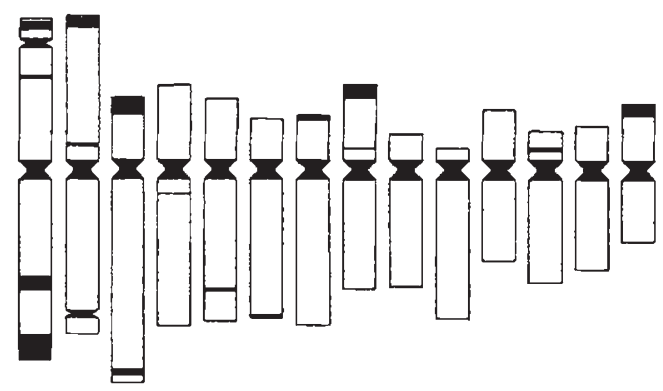

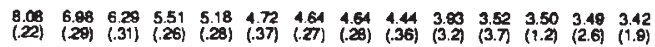

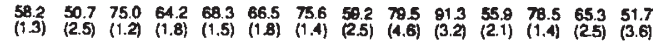
1ve 2ve 3ve 4ve 5ve 6ve 7ve Bve 9ve 10ve 11ve 12ve 13ve 14ve ↔

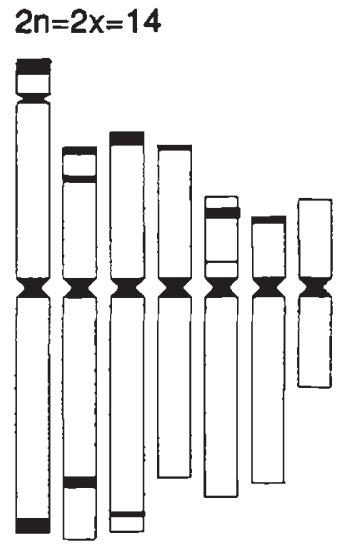

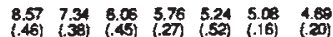
$\begin{array}{lllllll}54.1 & 56.1 & 59.8 & 61.8 & 60.8 & 62.8 & 48.8 \\ (1.3) & (1.6) & (1.8) & (2.5) & (3.2) & (1.5) & (2.1)\end{array}$

Ipa IIpa IIIpaIVpa Vpa VIpa Vilpa

$2 n=2 x=14$

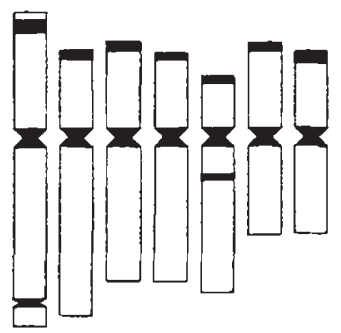

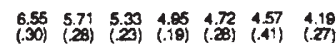

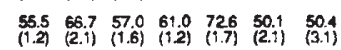
L. Ipr Hor Hipr IVor Vor Vipr Vilpr

L. ochroleucus $2 n=2 x=14$

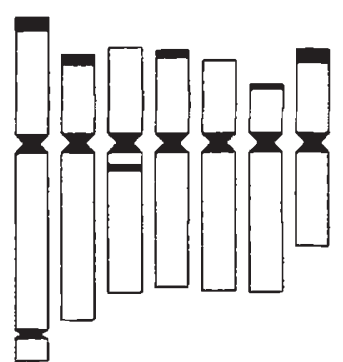

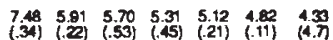

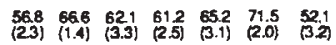

loc lloc HloclVoc Voc Vloc Viloc

Fig. 1 Idiograms of four species of genus Lathyrus. $\mathrm{C}_{1}$ : centromeric index; L: total length. Values in parentheses are standard deviations. Bar $=1 \mu \mathrm{m}$. 
(a)

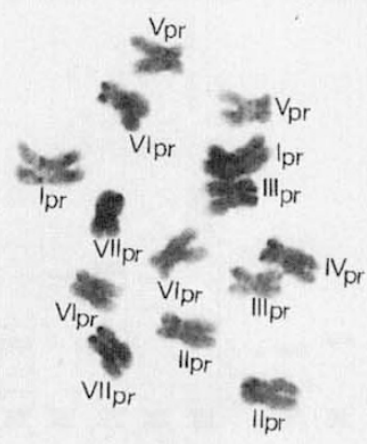

(c)

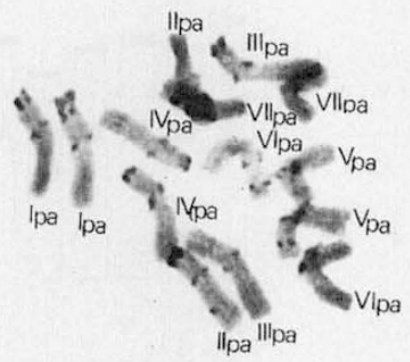

(e)

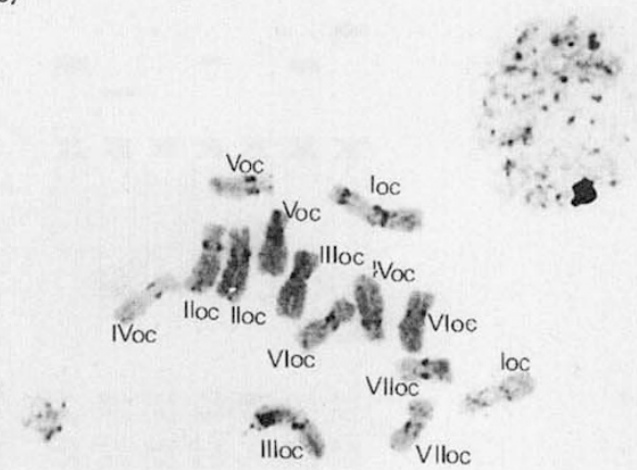

(b)

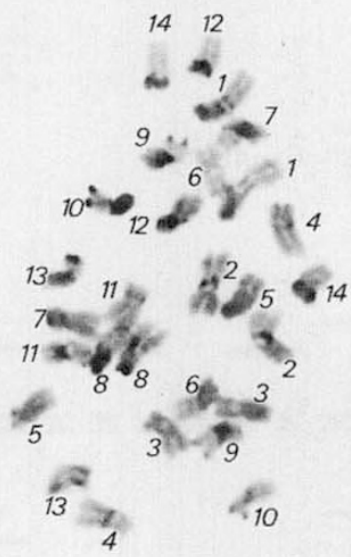

(d)

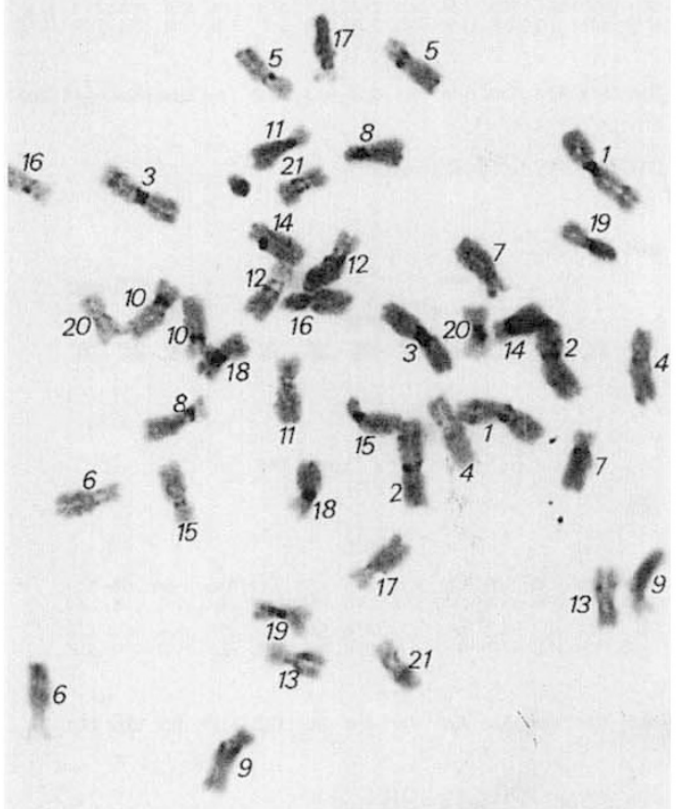

(f)

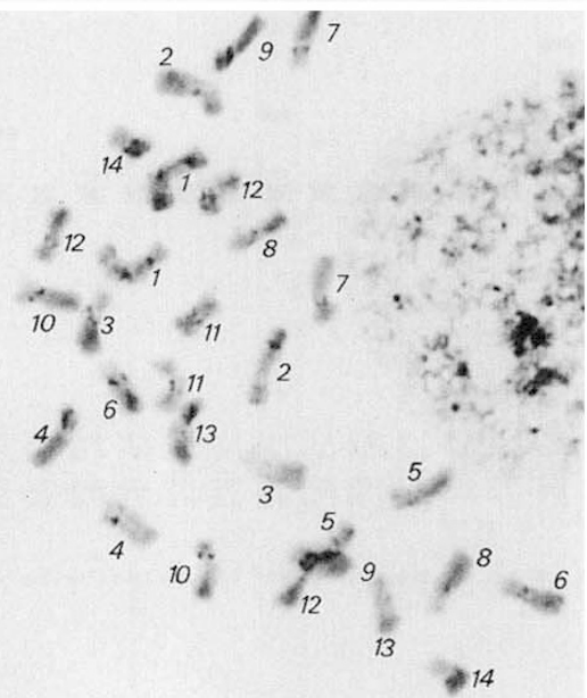

Fig. 2 C-banding metaphase plates. (a) L. pratensis $2 n=2 x=14$, (b) L. pratensis $2 n=4 x=28$, (c) L. palustris $2 n=2 x=14$, (d) L. palustris $2 n=6 \mathrm{x}=42$, (e) L. ochroleucus $2 n=2 \mathrm{x}=14$, (f) L. venosus $2 n=4 \mathrm{x}=28$. 
heterochromatin in the short arm, telomeric heterochromatin in the long arm, proximal interstitial heterochromatin in the long arm, distal interstitial heterochromatin in the long arm, proximal interstitial heterochromatin in the short arm, distal interstitial heterochromatin in the short arm, a satellite in the short arm, a satellite in the long arm, heterochromatin in a short arm satellite, heterochromatin in a long arm satellite, relative length.

The karyotypes (Fig. 1) were obtained from at least three different metaphase plates per plant and 12 plants per accession.

Chromosomal similarities and groupings among chromosomes of different ploidy levels and species were determined by cluster analysis, carried out by the BMDP-2M FORTRAN program (Engelman, 1983), of the 12 chromosomal characters described above. The probability of correct grouping was tested with a discriminant analysis by the BMDP-7M FORTRAN program (Jenrich \& Sampson, 1983).

\section{Electrophoretic methods}

Crude extracts from cataphyls of 15-20-days old seedlings (40-50 seeds per accession) were analysed by horizontal starch gel electrophoresis for 11 loci belonging to six different isozymatic systems: glutamic oxaloacetic transaminase (GOT, E.C. 2.6.1.1), phosphoglucose isomerase (PGI, E.C. 5.3.1.9), peroxidases (PRX, E.C. 1.11.1.7), leucine aminopeptidase (LAP, E.C. 3.4.11.1), malic dehydrogenase (MDH, E.C. 1.1.1.37) and phosphogluconic dehydrogenase (PGD, E.C. 1.1.1.44). The methods used for electrophoresis and staining were those described by Vences et al. (1987).

The allelic and genotypic frequencies obtained from the electrophoretic data were utilized to estimate unbiased genetic distances (Nei, 1973) and genotypic similarities (Hedrick, 1971), respectively. Phenograms were obtained by the Unweighted Pair Group Method clustering analysis (Sneath \& Sokal, 1973).

\section{Results and discussion}

\section{Karyotype construction}

Prior to karyotype construction (Figs 1 and 2) we checked the chromosome numbers of each sample in several metaphase plates. In all cases the observed and expected chromosome numbers coincided and no variability within an accession was ever detected (Table 1).

Each chromosomal pair was identified by the 12 chromosomal characteristics observed in the four species analysed (Fig. 2). A Roman numeral was assigned to each of the chromosomes of diploid species and an Arabic numeral to the chromosomes of polyploid species (Figs 1 and 2). In both cases the smallest numeral was assigned to the largest chromosome and the largest numeral to the smallest one.

\section{Chromosomal relationships}

Apart from genetic factors at least three factors related to the life cycle of these species prevented hybridization between species or between populations of the same species with different ploidy levels. The dormancy period of seeds extended to several months and germination induction by mechanical or chemical treatments was generally unsuccessful. The vegetative phase prior to the onset of flowering was also very long (in some cases 3 years). Finally, the small number of plants that flowered did not coincide in flowering time, thus preventing hybridization. In conclusion, all these phenomena made it impossible to carry out chromosome analyses at meiosis that would have shown homologous or homeologous relationships between chromosomes at different levels (species or ploidy). The difficulty in obtaining interspecific hybrids has been pointed out previously by Hitchcock (1952) and Kupicha (1983), who studied hybrids between North American species which are also unusual in often being polyploids.

To overcome all these problems we decided to establish by statistical methods the similarities between the chromosomes of diploid and polyploid populations of $L$. pratensis and L. palustris, between the chromosomes of polyploid populations within the species and between the chromosomes.

Statistical analyses were performed using the 12 chromosomal characters cited above and all characters were weighted equally. Firstly, we studied the chromosomes by cluster analysis and from the dendrogram obtained we established different groups of similarity (Fig. 3). Secondly, we checked the reliability of the groupings by a discriminant analysis because this method considers not only the similarities between the chromosomes but also the statistical variance within and between groups. In this way the best grouping was obtained when the intragroup variances was minimum but the intergroup variance was maximum (Table 2).

Cluster analysis of the 12 qualitative and quantitative chromosomal characters (Fig. 3) of polyploid accessions of $L$. pratensis $(2 n=4 \mathrm{x}=28)$ and $L$. palustris $(2 n=6 \mathrm{x}=42)$ yielded obvious groups of chromosomal similarity for morphology, size and C-banding pattern. However, in the tetraploid $L$. venosus no logical groups of chromosomal similarity were observed (Fig. 3). 
In tetraploid $L$. pratensis the cluster analysis showed six groups of close similarity for the 14 chromosome pairs (Fig. 3). Each group contains a pair of chromosomes: $1_{p r}-2_{p r}, 3_{p r}-4_{p r}, 5_{p r}-6_{p r}, 9_{p r}-10_{p r}, 11_{p r}-12_{p r}, 13_{p r}$ $14_{p r}$. The probabilities of successful groupings supplied by the discriminant analysis were very high $(P>0.947)$ in these six groups (Table 2). Nevertheless, chromosomes $7_{p r}$ and $8_{p r}$ are grouped independently by both statistical methods. In any case the probabilities supplied by discriminant analysis were higher for these six groups than for any other possible chromosome combinations.

On the other hand, some of the hypothetical groups established by the cluster analysis between diploid and tetraploid chromosome complements of $L$. pratensis are ambiguous (Fig. 3) because they include some of the polyploid chromosome pairs previously indicated and two chromosomes of diploid complement $\left(\mathrm{III}_{p r^{-}}\right.$ $\mathrm{IV}_{p r}-5_{p r}-6_{p r}$ ) while chromosomes $13_{p r}-14_{p r}$ and $9_{p r}-10_{p r}$ group with $\mathrm{VI}_{p r}-\mathrm{VII}_{p r}$. Nevertheless, the other two groups seem to be sufficiently defined $\left(\mathrm{I}_{p r}-1_{p r}-2_{p r}, \mathrm{II}_{p r}-\right.$ $3_{p r}-4_{p r}$ by this analysis.

The results of discriminant analysis between diploid and tetraploid complements of $L$. pratensis (Table 2) supplied four groups of high similarity $\left(\mathrm{I}_{p r}-1_{p r}-2_{p r}, \mathrm{II}_{p r}\right.$ $3_{p r}-4_{p r}, \mathrm{IV}_{p r}-5_{p r}-6_{p r}$, and $\left.\mathrm{V}_{p r}-7_{p r}-8_{p r} ; P>0.9\right)$. However, the last group must be rejected because morphological similarity between these chromosomes is minimal (Figs 1 and 3). The grouping could be considered a spurious by-product generated by the discriminant analysis itself (intragroup variance vs. intergroup variance).

In hexaploid $L$. palustris cluster analysis differentiated (Fig. 3) five groups of similarity, including three different chromosomes in each one $\left(1_{p a}-2_{p u}-3_{p a}, 4_{p a}\right.$ $\left.5_{p a}-6_{p u}, 9_{p u}-17_{p u}-18_{p u}, 13_{p u}-14_{p u}-15_{p u}, 19_{p u}-20_{p a}-21_{p a}\right)$. Discriminant analysis supplied the highest probability of correct grouping for each one of this group (Table 2).

Cluster analysis between diploid and hexaploid complements (Fig. 3) showed three well-defined chromosome groups $\left(\mathbf{I}_{p a}-1_{p a}-2_{p u}-3_{p a}, \mathrm{II}_{p a}-4_{p u}-5_{p a}-6_{p u}\right.$, $\left.\mathrm{VI}_{p a}-9_{p a}-17_{p a}-18_{p a}\right)$. Two other groups $\left(\mathrm{V}_{p a}-13_{p a}-14_{p a}^{-}\right.$ $15_{p a}$, VII ${ }_{p a}-19_{p a}-20_{p a}-21_{p a}$, although sufficiently well defined, are distorted to some extent by the inclusion of chromosomes $10_{p a}-11_{p a}$ and $I V_{p a}$, respectively (Fig. 3 ). Discriminant analysis confirms the five groups of chromosomes with high values of probability ranging narrowly between 0.833 and 1.000 for the three former groups, and between 0.995 and 1.000 for the two latter ones (Table 2).

As indicated above, cluster analysis in $L$. venosus (Fig. 3) supplied no useful results to establish the similarity between chromosomes of the tetraploid species. Nevertheless, with this method we were able to identify four groups of chromosomal similarity between diploid $L$. palustris and $L$. venosus $\left(\mathrm{I}_{p u}-1_{v e}, \mathrm{III}_{p a}-3_{v e}, \mathrm{~V}_{p a}-7_{v e}\right.$, $\left.\mathrm{VII}_{p q}-11_{v e}\right)$ and another four between $L$. ochroleucus and L. venosus $\left(\mathrm{I}_{o c}-2_{v e}, \mathrm{III}_{o c}-4_{v e}, \mathrm{VII}_{o c}-14_{v e}, \mathrm{~V}_{o c}-13_{v e}\right)$ (Fig. 3). The probability of correct pairing ranged between 0.806 and 1.000 for the first group and between 0.689 and 0.988 for the second group (Table 2 ). Since the probability was very low for the $\mathrm{V}_{o c}-13_{v e}$ pair it was rejected.

From these statistical analyses we conclude that the polyploid populations of $L$. pratensis and $L$. palustris are of autopolyploid origin. They further suggest an allopolyploid origin for $L$. venosus because we can statistically establish several groups of chromosomal similarity at different levels of comparison. The autotetraploid nature of $L$. pratensis is further suggested by the quadrivalent configurations in the meiosis of tetraploid individuals (Brunsberg, 1977).

However, some chromosomes of diploid complements are not, or are only slightly similar to, chromosome groups of polyploid species. Moreover, some related chromosomes did not show identical chromosomal morphology and C-banding pattern. These results can be explained from general and specific arguments. First and foremost, the rejection of polyploid evolution as a simple process of doubling the chromosome numbers as this quantitative change in chromosome number and nuclear DNA content is only one of a series of complex processes that must take place for polyploidy to be successful in nature. Secondly, hybridization that produces genetic and/or chromosomal heterozygosity, mutation to be a different ploidy level and gene-controlled regularization of chromosome pairing are all changes as important for successful polyploid evolution as is the doubling or trebling of the chromosome number. In this way we must always distinguish between polyploidy as an individual process and polyploid evolution as a complex series of processes (Stebbins, 1980). An example of the great importance of hybridization processes for the success of polyploids is the multiple origins of several polyploid plant species (auto- and allopolyploid) described by Soltis et al. (1991). On the other hand, the evolution of the genus Lathyrus has been associated with an increase in 2C nuclear DNA amounts (Rees \& Durrant, 1986; Narayan, 1991). Even though there is no correlation between genome size and total chiasma frequency between species in Lathyrus, within complements chiasma frequency increases proportionally to the amount of DNA in the chromosomes (Narayan \& McIntyre, 1989). Thus we must not expect the original chromosome structure of progenitor species to remain. 

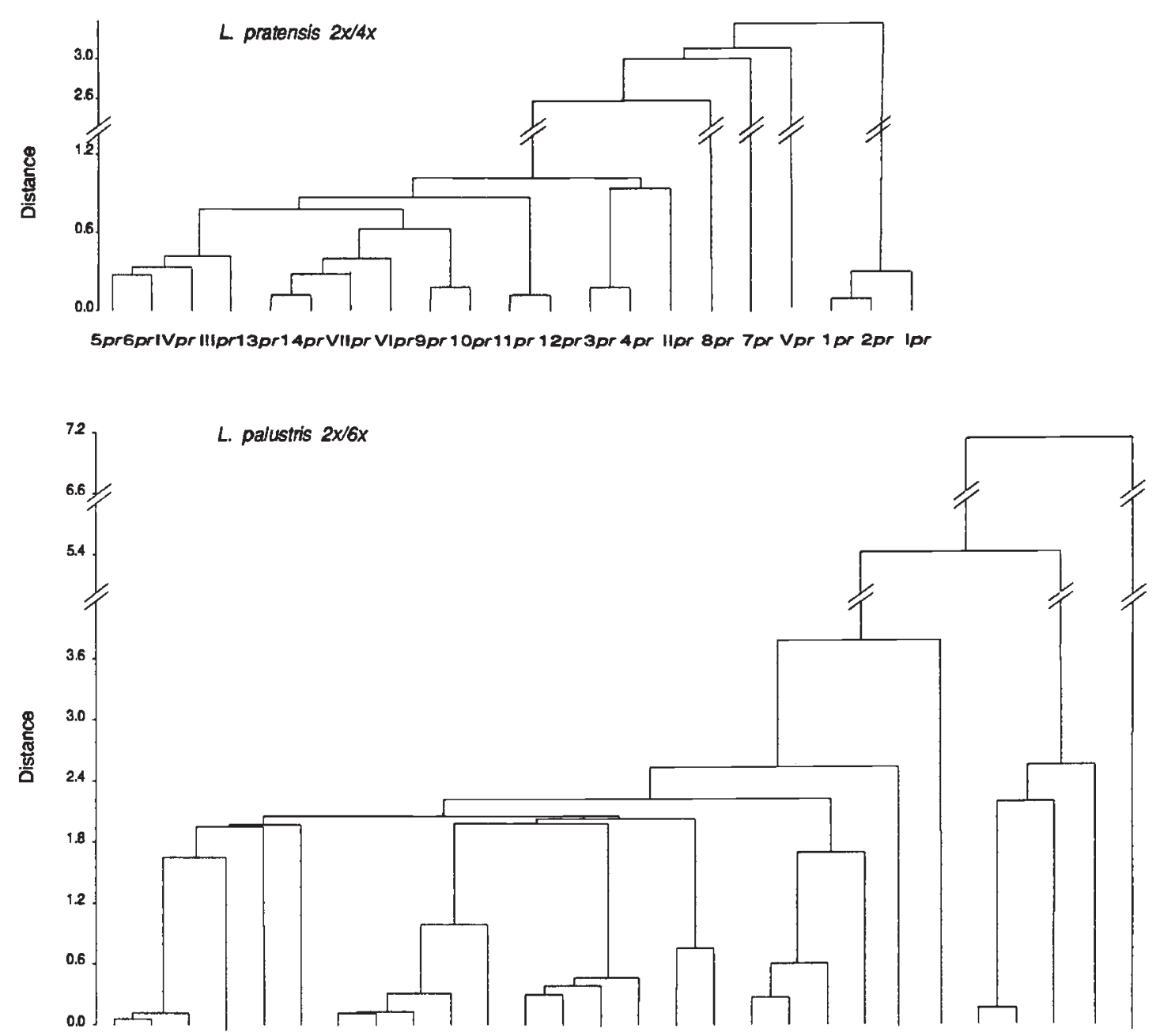

13pa14pa 15pa10pa $11 p a$ Vpa 20pa21pa 19pa VIlpaIVpa 17pa 18pa Vipa 9pa 8pa lllpa 4pa 5pa llpa 6pa 12pa 7pa 2pa 3pa 1pa lpa 16pa

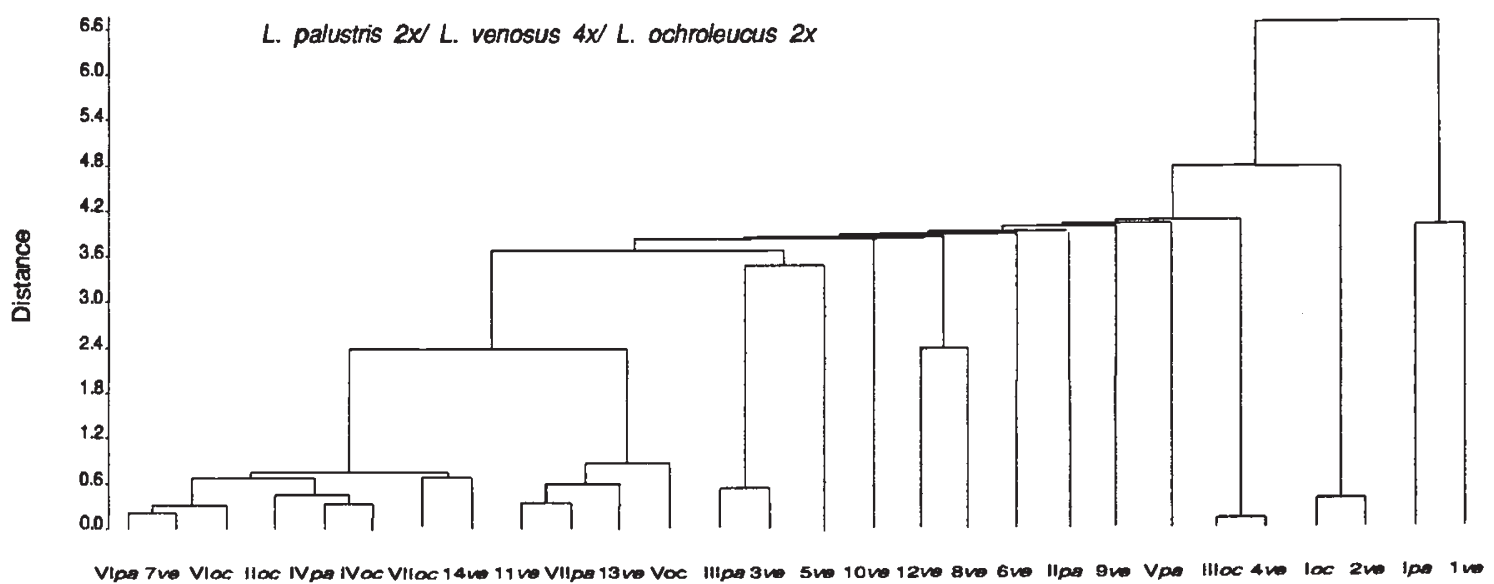

Fig. 3 Chromosomal cluster analysis of different ploidy levels. Roman numerals: chromosomes of diploid karyotypes; Arabic numerals: chromosomes of polyploid karyotypes. 
Table 2 Probability of successful grouping between chromosomes of different ploidy levels or species

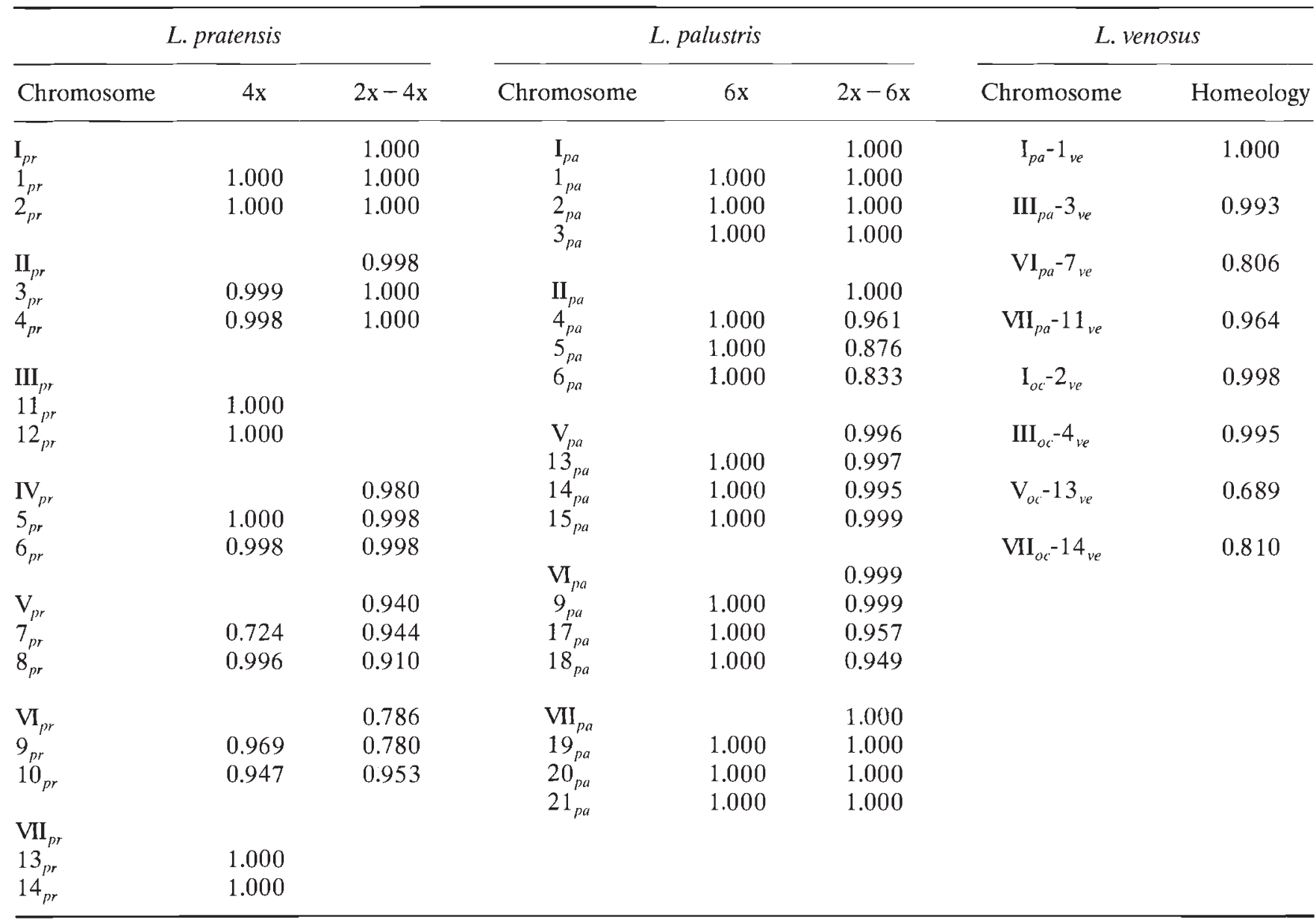

Roman numerals indicate chromosomes belonging to diploid karyotypes, arabic numerals refer to polyploid karyotypes.

\section{Genetic similarity}

As similarity for isozyme loci was estimated at the genetic level, we needed to know the genetic control of different isozyme loci. To achieve this we used the genetic control deduced from several $\mathrm{F}_{1}, \mathrm{~F}_{2}$ and backcrossed progenies in grass pea (L. sativus L.) (Vences \& Gutiérrez, 1992; Gutiérrez \& Vences, 1993). This was possible because previously we had checked the electrophoretic mobility of the alleles of the species analysed and also the counterparts in grass pea. We found that all isozymatic phenotypes observed in $L$. pratensis, $L$. palustris, $L$. venosus and $L$. ochroleucus could be explained either by a combination of the different alleles described in grass pea or combinations of these same alleles and some others specific to each species (Fig. 4, Table 3).

From the allele and genotypic frequencies two different algorithms were calculated for each isozymatic locus analysed: the genetic distance (Nei,
1973) and genotypic similarity (Hedrick, 1971) indices, respectively.

The phenograms obtained from these two algorithms by the UPGMA method (Fig. 5) group all samples of $L$. pratensis into the same cluster $(p r)$, while samples belonging to the other three species are included in another one ( $p a, v e, o c)$. Nevertheless, in this latter cluster the three species are clearly distinguishable because accessions belonging to the different species separate into three well-defined groups.

We found notably high genetic similarities between $L$. venosus and $L$. palustris (Table 4 ) and between $L$. venosus and L. ochroleucus (Table 4), which are higher than that observed at the interspecific level in other plant species for isozyme loci (Ayala, 1981). Since a close similarity between these three species has been reported previously for various characteristics such as geographical distribution (Kupicha, 1983), morphology (Hitchcock, 1952; Kupicha, 1983) and biochemi- 

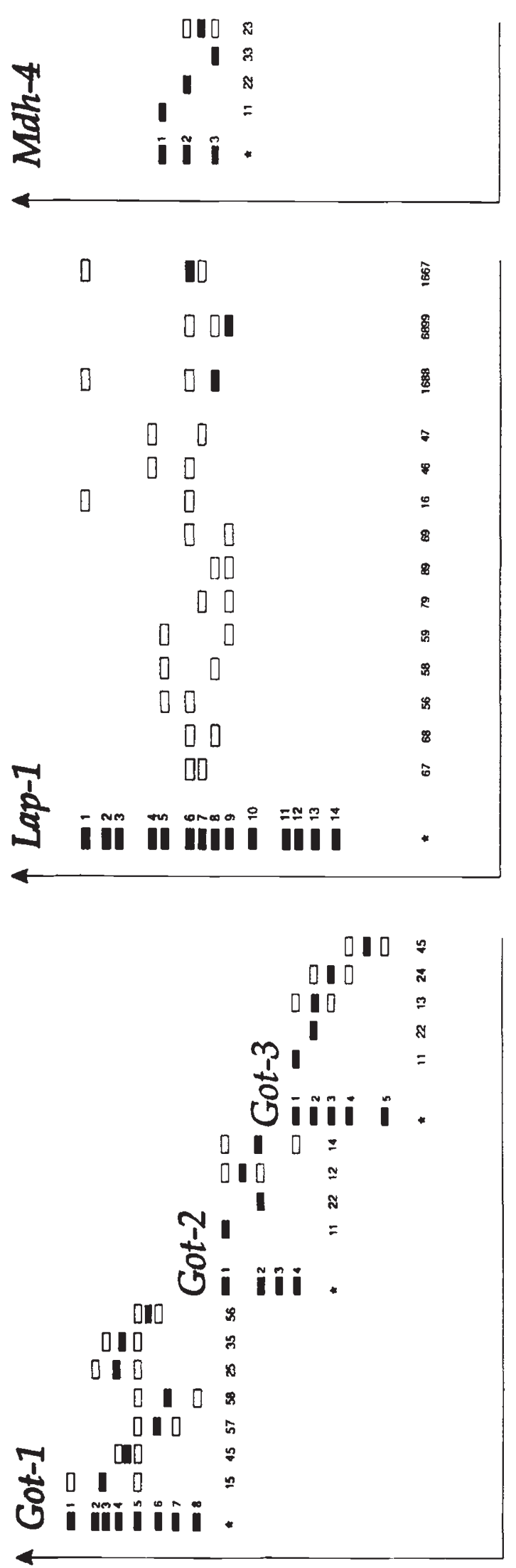

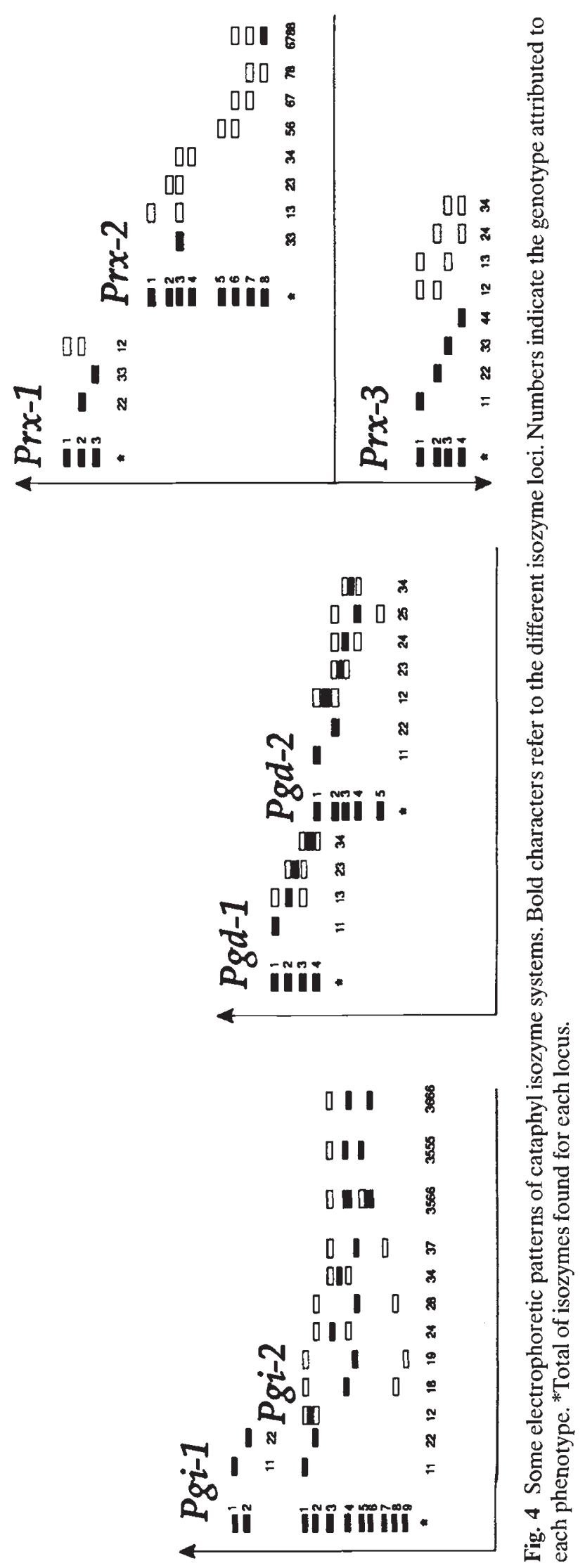


Table 3 Genetic control and allele distribution of different isozymatic loci analysed

\begin{tabular}{|c|c|c|c|c|c|c|c|c|c|c|c|c|c|c|c|c|c|}
\hline \multirow[b]{2}{*}{ Locus } & \multirow[b]{2}{*}{ Control } & \multirow[b]{2}{*}{$A$} & \multirow{2}{*}{$\begin{array}{l}o c \\
2 \mathrm{x}\end{array}$} & \multicolumn{2}{|c|}{$p a$} & \multicolumn{2}{|c|}{$p r$} & \multirow{2}{*}{$\begin{array}{l}v e \\
4 \mathrm{x}\end{array}$} & \multirow[b]{2}{*}{ Locus } & \multirow[b]{2}{*}{ Control } & \multirow[b]{2}{*}{$A$} & \multirow{2}{*}{$\begin{array}{l}o c \\
2 \mathrm{x}\end{array}$} & \multicolumn{2}{|c|}{$p a$} & \multicolumn{2}{|c|}{$p r$} & \multirow{2}{*}{$\begin{array}{l}v e \\
4 \mathrm{x}\end{array}$} \\
\hline & & & & $2 x$ & $6 x$ & $2 x$ & $4 x$ & & & & & & $2 x$ & $6 x$ & $2 x$ & $4 x$ & \\
\hline \multirow[t]{8}{*}{ Got-1 } & Digenic & 1 & - & - & - & - & + & - & Pgi-1 & Monogenic & 1 & - & + & - & + & + & - \\
\hline & & 2 & - & - & - & + & + & - & & & 2 & + & + & + & - & - & + \\
\hline & & 3 & + & + & + & + & + & + & $P g i-2$ & Digenic & 1 & + & - & - & - & - & + \\
\hline & & 4 & - & - & - & + & + & + & & & 2 & + & + & + & - & - & + \\
\hline & & 5 & - & + & + & - & + & + & & & 3 & - & - & - & + & + & - \\
\hline & & 6 & + & + & - & - & - & - & & & 4 & - & + & + & + & + & - \\
\hline & & 7 & - & - & - & - & - & + & & & 5 & - & - & - & + & + & - \\
\hline & & 8 & + & + & + & - & - & + & & & 6 & - & - & - & + & + & - \\
\hline \multirow{4}{*}{ Got-2 } & Digenic & 1 & + & - & - & + & + & + & & & 7 & - & - & - & + & + & - \\
\hline & & 2 & - & - & - & + & + & - & & & 8 & + & + & + & - & - & + \\
\hline & & 3 & - & + & + & + & + & - & & & 9 & + & - & - & - & - & + \\
\hline & & 4 & + & + & + & - & - & + & Pgd-I & Digenic & 1 & + & + & + & + & + & + \\
\hline \multirow[t]{5}{*}{ Got-3 } & Digenic & 1 & - & - & - & + & + & + & & & 2 & + & + & - & - & + & + \\
\hline & & 2 & + & + & + & - & - & + & & & 3 & + & + & + & + & + & + \\
\hline & & 3 & - & + & + & + & + & - & & & 4 & - & - & - & - & + & - \\
\hline & & 4 & + & + & + & - & - & + & $P g d-2$ & Digenic & 1 & - & - & + & - & + & + \\
\hline & & 5 & + & - & - & - & - & - & & & 2 & + & + & - & + & + & + \\
\hline \multirow[t]{14}{*}{ Lap-1 } & Monogenic & 1 & - & - & - & - & + & - & & & 3 & + & + & + & - & + & + \\
\hline & & 2 & - & + & - & - & - & + & & & 4 & - & + & + & + & + & + \\
\hline & & 3 & - & + & + & - & - & + & & & 5 & - & + & - & - & + & + \\
\hline & & 4 & - & - & + & - & - & + & Prx-1 & Monogenic & 1 & - & + & + & - & - & + \\
\hline & & 5 & - & - & - & + & + & + & & & 2 & + & - & - & - & - & + \\
\hline & & 6 & - & - & - & + & + & + & & & 3 & - & + & - & + & + & - \\
\hline & & 7 & - & - & - & + & + & + & Prx -2 & Monogenic & 1 & - & - & + & - & - & - \\
\hline & & 8 & - & - & - & + & + & + & & & 2 & - & - & - & + & + & - \\
\hline & & 9 & + & + & + & + & + & + & & & 3 & - & - & - & + & + & - \\
\hline & & 10 & + & - & + & - & - & + & & & 4 & - & + & - & + & + & - \\
\hline & & 11 & + & + & + & - & - & + & & & 5 & - & + & - & - & - & - \\
\hline & & 12 & - & - & - & - & - & + & & & 6 & + & + & + & - & - & + \\
\hline & & 13 & - & + & - & - & - & + & & & 7 & + & + & + & - & - & + \\
\hline & & 14 & - & - & - & - & - & + & & & 8 & + & - & + & - & - & + \\
\hline \multirow{4}{*}{$M d h-4$} & Digenic & 1 & + & + & + & - & - & + & Prx -3 & Monogenic & 1 & + & + & - & - & + & + \\
\hline & & 2 & - & - & - & + & + & - & & & 2 & - & - & - & + & + & - \\
\hline & & 3 & - & - & - & + & - & - & & & 3 & + & + & - & + & + & + \\
\hline & & & & & & & & & & & 4 & + & + & + & - & + & + \\
\hline
\end{tabular}

$A$ : allele; +: presence; $-:$ absence; ve: L. venosus; pr: L. pratensis; oc: L. ochroleucus; pa: L. palustris; $2 \mathrm{x}, 4 \mathrm{x}$ and $6 \mathrm{x}$ : diploid, tetraploid and hexaploid accessions, respectively.

cal markers (Simola, 1968), the allopolyploid origin of $L$. venosus from $L$. ochroleucus and L. palustris proposed by Stebbins (personal communication) seems to be consistently supported.

At the intraspecific level both indices indicate a very high genetic similarity in agreement with those reported by other authors for several plant species; this is so even between samples of the same species but with different ploidy levels. This fact is a logical result because the different ploidy levels create a strong isolating barrier between diploid and polyploid popu- lations and high genetic divergence would not be required to prevent hybridization between the two levels (Ayala, 1981).

However, the Hedrick index suggests that the genotypic structure of diploid populations of $L$. pratensis and L. palustris is different from their polyploid populations. Thus we can see (Fig. 5) that diploid populations group preferentially together and are only slightly mixed with polyploid populations. Likewise, some authors (Brunsberg, 1977) have considered, from morphological characteristics, that diploid and tetra- 
Fig. 5 Phenograms obtained from genotypic similarity index (Hedrick, 1971) and genetic distance index (Nei, 1973). *Polyploid accessions. pr: $L$. pratensis; pa: L. palustris; ve: $L$. venosus; oc: L. ochroleucus.
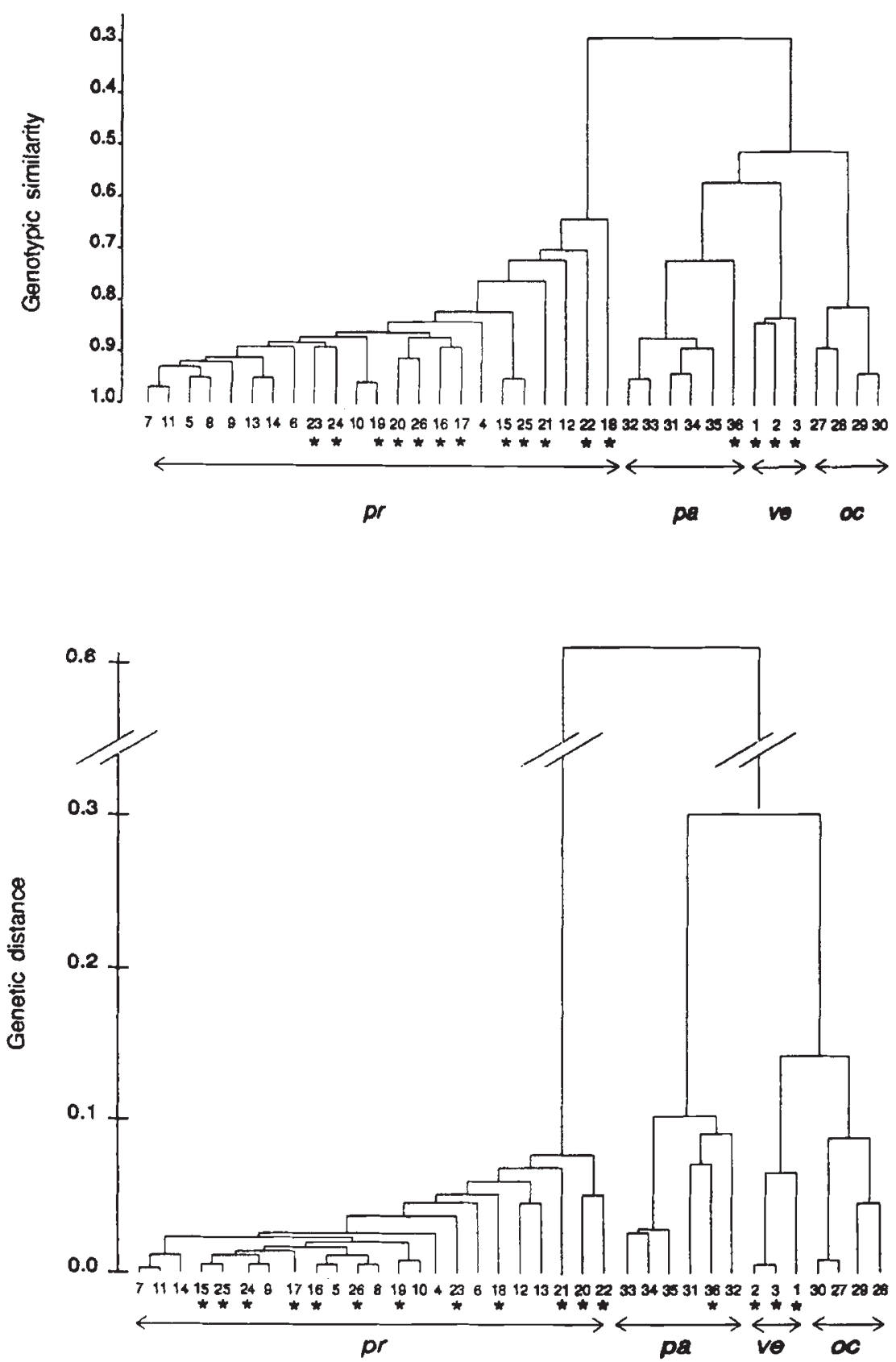

ploid populations of $L$. pratensis are two different ecotypes (subspecies) of the same species. Since almost all isozymatic alleles of diploid $L$. pratensis samples are also present in tetraploid samples and the genetic similarity between both ploidy levels is very high, the autopolyploid origin of tetraploid populations of $L$. pratensis could be a logical conclusion.

Unfortunately, we have analysed only one polyploid sample of $L$. palustris but the genotypic similarity (see Fig. 5) is similar to several comparisons among diploid and tetraploid samples of $L$. pratensis. For this reason, an autopolyploid origin for the hexaploid population could also be possible.

In conclusion, the results of our isozyme analysis and cytogenetic studies support the allopolyploid origin of $L$. venosus from the two sympatric species $L$. palustris and L. ochroleucus and also the autopolyploid origin of tetraploid L. pratensis and hexaploid L. palustris. 
Table 4 (a) Nei's genetic distance at specific level, (b) Hedrick's genotypic similarity at specific level

\begin{tabular}{lcccc}
\hline Species & L.oc. & L.pa. & L.pr. & L.ve. \\
\hline (a) & & & & \\
L. ochroleucus & 0.075 & & & \\
L. palustris & 0.360 & 0.108 & & \\
L. pratensis & 0.650 & 0.587 & 0.022 & \\
L. venosus & 0.225 & 0.230 & 0.616 & 0.058 \\
(b) & & & & \\
L. ochroleucus & 0.843 & & & \\
L. palustris & 0.492 & 0.835 & & \\
L. pratensis & 0.149 & 0.132 & 0.832 & \\
L. venosus & 0.558 & 0.573 & 0.132 & 0.834 \\
\hline
\end{tabular}

For abbreviations, see Table 3.

\section{Acknowledgements}

This work has been supported by a grant from the P.F.P.I. (Gutiérrez). We are specially grateful to Professor G. L. Stebbins for his suggestions and also to Dr P. García for his helpful criticisms.

\section{References}

ALKIN, R., MACFARLANE, T. D., WITHE, R. F., BISBY, F. A. AND ADEY, M. E. 1985. The geographical distribution of Lathyrus. Viciae Database project publication (2), Southampton.

ALVAREZ, M. T., FOMinAYA, A. AND PEREZ DE LA VEGA, M. 1991. A possible effect of B-chromosomes on metaphase-I homologous chromosome association in rye. Heredity, 67, 123-128.

AYALA, F. J. 1981. Gradualism versus punctualism in speciation: reproductive isolation, morphology, genetics. In: Barigozzi, C. (ed.) Mechanisms of Speciation, pp. 51-66. A. R. Liss, New York.

BRUNSBERG, K. 1977. Biosystematics of the Lathyrus pratensis complex. Opera Bot., 42, 1-78.

ENGELMAN, L. 1983. Cluster analysis of cases. In: University of California Press (ed.) BMDP Statistical Software, pp. 456-463. University of California Press, Berkeley.
GUTIERrEZ, J. F. AND vENCES, F. J. 1993. Grass pea (Lathyrus sativus L.): use of molecular markers and future implications in the eradication of lathyrism. Proceedings on Conservation and Use of Genetic Resources, Madrid, Spain.

HEDRICK, P. W. 1971. An approach to measuring genetic similarity. Evolution, 25, 276-280.

HITCHCOCK, C. L. 1952. A revision of the North American species of Lathyrus. University of Washington Publications in Biology, 15, 1-104.

JENRICH, R. AND SAMPSON, P. 1983. Stepwise discriminant analysis. In: University of California Press (ed.) $B M D P$ Statistical Software, pp. 519-553. University of California Press, Berkeley.

KUPICHA, F. K. 1983. The intragenetic structure of Lathyrus. Notes R. B. G. Edinb., 41, 209-244.

NARAYAN, R. K. J. 1991. Molecular organization of the plant genome: its relation to structure, recombination and evolution of chromosomes. J. Genet., 70, 43-62.

NARAYAN, R. K. J. AND MCINTYRE, F. K. 1989. Chromosomal DNA variation, genomic constraints and recombination in Lathyrus. Genetica, 79, 45-52.

NEJ, M. 1973. Analysis of gene diversity populations. Proc. Natl. Acad. Sci. U.S.A., 70, 3321-3323.

REES, H. AND DURRANT, G. 1986. Recombination and genome size. Theor. Appl. Genet., 73, 72-76.

SIMOLA, L. K. 1968. Comparative studies on the number of leaflets, venation and epidermal structure in the genus Lathyrus. Can. J. Bot., 46, 71-84.

SNEATH, P. H. A. AND SOKAL, R. R. 1973. Numerical Taxonomy. W. H. Freeman, San Francisco.

SOLTIS, P. S., DOYLE, J. J. AND SOLTIS, D. E. 1991. Molecular data and polyploid evolution in plants. In: Soltis, P. S., Doyle, J. J. and Soltis, D. E. (eds) Molecular Systematics of Plants, pp. 177-201. Chapman and Hall, New York.

STEBBins, G. L. 1980. Polyploidy in plants: unsolved problems and prospects. In: Lewis, W. H. (ed.) Polyploidy: Biological Relevance, pp. 495-520. Plenum Press, New York.

STEBBINS, G. L. 1989. Evolución, hacia una nueva síntesis: contribuciones desde el reino vegetal. Universidad de León, León.

VENCES, F. J., VAQUERO, F. AND PEREZ DE LA VEGA, M. 1987. Phylogenetic relationships in Secale (Poaceae): an isozymatic study. Pl. Syst. Evol, 157, 33-47.

VENCES, F. J. AND GUTIÉRREZ, J. F. 1992. Genetic control of isoenzymatic loci in grass pea Lathyrus sativus L. Second International Food Legume Research Conference (IFLRCII), Cairo, Egypt. 